\title{
A RARE GERMLINE LEU63PRO MISSENSE MUTATION IN CDC73 RESULTING IN FAMILIAL PRIMARY HYPERPARATHYROIDISM WITH VARIABLE PHENOTYPE
}

\author{
K Seejore, $R$ Murray, S Orme and A Abbas \\ Department of Endocrinology, St James's University Hospital, Leeds, United Kingdom
}

\section{INTRODUCTION}

Primary hyperparathyroidism (PHPT) is a common endocrine disorder. However, a familial hyperparathyroid syndrome is diagnosed in less than five percent of cases.

We present two related cases of CDC73-related familial hyperparathyroidism due to a rarely described germline Leu63Pro missense mutation in $C D C 73$ exon 2.

\section{CASE REPORT}

The index patient, a 24-year old female, presented acutely unwell with symptoms of hypercalcaemia. Her blood tests showed PTH $186.1 \mathrm{pmol} / \mathrm{L}$ (1.5-7.6) with calcium $4.20 \mathrm{mmol} / \mathrm{L}$ (2.2-2.6). Parathyroid imaging demonstrated bilateral parathyroid adenomas. Her life-threatening hypercalcaemia was treated with intravenous saline and bisphosphonates.

However despite treatment with cinacalcet, persistent severe symptomatic hypercalcaemia necessitated an urgent parathyroidectomy. All 4 parathyroid glands were excised. Her recovery was complicated by severe hungry bone syndrome.

The patient's parents are unaffected by hyperparathyroidism. However it transpired that her 35-year old brother had a history of resected Wilms' tumour aged 5. He also had PHPT with a left inferior parathyroid adenoma removed in 2008. Despite being initially lost to follow-up, he was subsequently re-referred with symptomatic recurrent PHPT (PTH 31.2 $\mathrm{pmol} / \mathrm{L}$, Ca $2.95 \mathrm{mmol} / \mathrm{L}$ ). He underwent repeat parathyroid surgery and one normally functioning parathyroid gland was left in-situ. In both cases, parathyroid histology was benign.

Further enquiry into the family history revealed that a paternal cousin also had hypercalcaemia and had more than one parathyroid glands removed. In addition, the paternal grandmother had also suffered from renal stones.

Genetic testing revealed germline Leu63Pro missense mutation in $C D C 73$ exon 2, gene coding for the parafibromin protein.

\begin{tabular}{|l|c|c|}
\hline Family Mutation & \multicolumn{2}{|c|}{ Leu63Pro missense } \\
\hline Patient & Sister & Brother \\
\hline $\begin{array}{l}\text { Age at diagnosis (yrs) } \\
\text { Corrected Ca (mmol/L) }\end{array}$ & 24 & 32 \\
\hline $\begin{array}{l}\text { Serum PTH (pmol/L) } \\
\text { No. of parathyroid tumours removed; } \\
\text { histology }\end{array}$ & 4.20 & 2.80 \\
\hline $\begin{array}{l}\text { Other non-parathyroid features } \\
\text { Hyperplasia }\end{array}$ & $\begin{array}{c}\text { Nil } \\
\text { adenoma }\end{array}$ \\
\hline
\end{tabular}

\section{DISCUSSION}

CDC73-related familial hyperparathyroidism encompasses a spectrum of parathyroid disorders including the following phenotypes:

- hyperparathyroidism-jaw tumour syndrome (HPT-JT)

- Parathyroid carcinoma

- Familial isolated hyperparathyroidism (FIHP)

HPT-JT is an autosomal dominant condition with incomplete penetrance, characterised by atypical parathyroid tumours ( $15 \%$ malignant) with tumours of one or more of the jaw, kidneys or uterus. Approximately 100 affected families have been reported in the medical literature.

CDC-73 (formerly known as HRPT2) is a gene that encodes the tumour suppressor protein parafibromin. More than 44 pathologic sequence variants have been described for $C D C-73$ and account for the spectrum of disorders. Most reported mutations are small deletions or insertions leading to truncation of the parafibromin protein. CDC-73 mutations have been implicated in the malignant transformation of parathyroid tumours.

CDC-73 mutations are predominantly found in exons 1, 2 and 7. Most mutations appear to be unique to individual families; however some mutations have been found in unrelated families. The CDC73 germline Leu63Pro missense mutation, documented in our case, was previously identified only once, in 2008 in an Italian kindred with FIHP.

Patients with HPT-JT are at high risk of recurrent parathyroid and non-parathyroid tumours and require long-term surveillance. Similarly, genetic testing must be offered to at-risk relatives starting around age 5-10 years if the family-specific CDC73 germline mutation is identified.

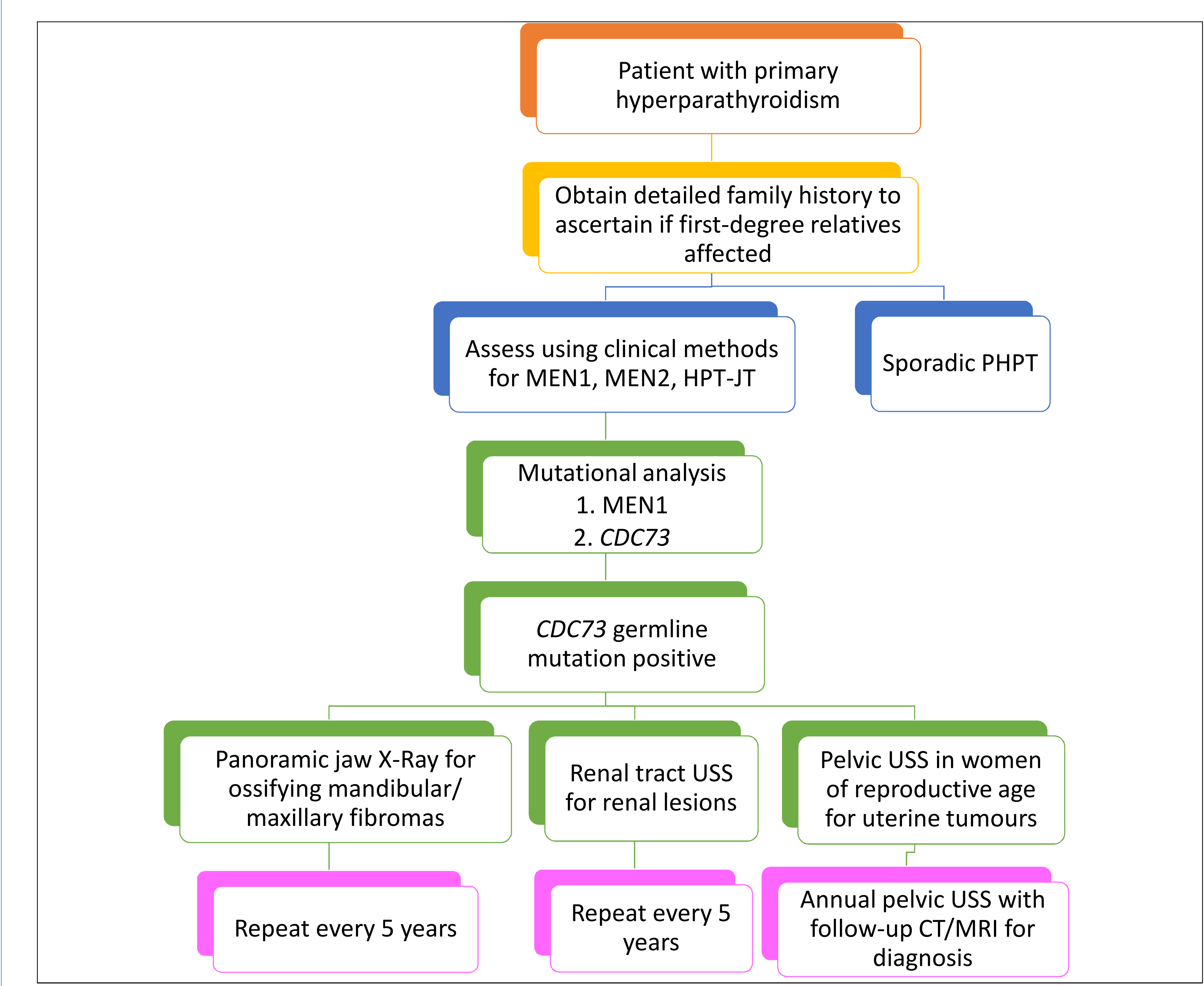

Figure 1: Diagnosis of and surveillance for CDC73 related disorders. Abbreviations: MEN, Multiple Endocrine Neoplasia

\section{REFERENCES}

. Familial isolated primary hyperparathyroidism caused by mutations of the MEN1

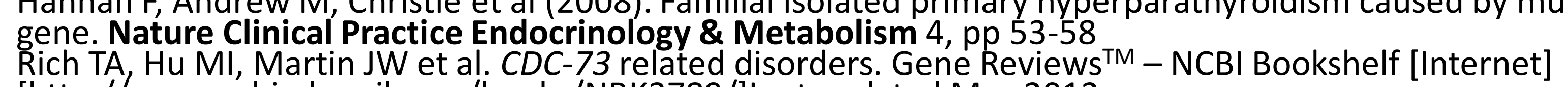

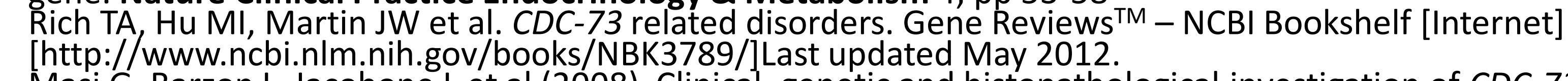

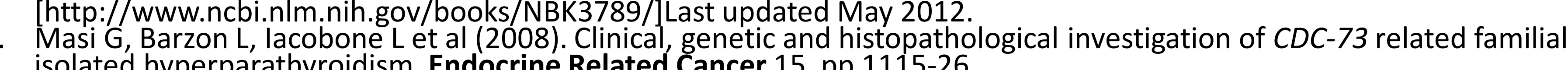
Isolated hyperparathyroidism. Endocrine Related Cancer 15, pp $1115-26$.
Bradley KJ et al. (2005) Uterine tumours are a phenotypic manifestation of the hyperparathyroidism-jaw tumour syndrome.
I Intern Med 257:18 